\title{
A educação sexual e a formação de professores/as um convite ao dissenso
}

\author{
Apoliana Regina GROFF ${ }^{1}$ \\ Kátia MAHEIRIE ${ }^{2}$ \\ Patrícia de Oliveira e Silva Pereira MENDES 3
}

\section{Introdução}

A educação sexual que se efetiva na Universidade do Estado de Santa Catarina, por meio de estudos nas Disciplinas do Curso de Pedagogia a Distância denominadas Educação e Sexualidade e Educação Sexual Interfaces Curriculares, coloca-se a dialogar com autores de tradição marxista cujo interesse volta-se para a tomada de consciência do sujeito no âmbito da sua sexualidade que é histórica, política e culturalmente significada. É a partir deste contexto de formação, onde a educação sexual se faz presente como campo de estudo, que nos situamos para

1 Doutora em Psicologia. UFSC - Universidade Federal de Santa Catarina - PósGraduação em Psicologia. Florianópolis - SC - Brasil. 88040-900 - poligroff@ gmail.com

2 Doutora em Psicologia Social. PUC - Pontifícia Universidade Católica de São Paulo - Pós-Graduação em Psicologia Social. São Paulo - SP - Brasil. 06414-007. UFSC - Universidade Federal de Santa Catarina - Departamento de Psicologia e no Programa de Pós-Graduação em Psicologia com estágio Pós-Doutoral em Educação pela UNICAMP. Florianópolis - SC - Brasil. 88040-900 - maheirie@gmail.com

3 Doutoranda em Psicologia. UFSC - Universidade Federal de Santa Catarina - PósGraduação em Psicologia. Florianópolis - SC - Brasil. 88040-900. UDESC Universidade do Estado de Santa Catarina. Centro de Educação a Distância. Florianópolis - SC - Brasil. 88035-001 - patpereiramendes@gmail.com 
entrelaçar olhares que se voltam à formação de professores, ao contexto escolar e às legislações e políticas educacionais.

Figueiró (2006) explicita que a abordagem da educação sexual voltada para a emancipação é uma abordagem política, cunhada pela estudiosa Maria Amélia Goldberg ${ }^{4}$, no Brasil, na década de 80. Para essas autoras a educação sexual nos espaços educativos formais e não formais precisa possibilitar uma compreensão consciente da sexualidade em todas as suas expressóes e vivências, para que os/ as estudantes possam se posicionar criticamente com relaçáo à amplitude de questôes sociais, políticas e culturais que envolvem a sexualidade.

Atualmente encontramos interlocuçôes com autores pós-estruturalistas que corroboram para a compreensão da sexualidade em suas implicaçóes geracionais, de raça, de nacionalidade, étnicas, religiosas, de classes e que explicitam as muitas formas de nos constituirmos como homens, mulheres, transgêneros e mesmo numa corporeidade não binária, ampliando, assim, os estudos acerca da educação sexual e das "pedagogias da sexualidade". Por pedagogias da sexualidade, Louro (2007) compreende as formas de apropriação dos discursos sobre os corpos e a sexualidade, que normatizam e regulam aquilo do que se pode falar ou se deve silenciar, ou ainda, quem pode falar e quem náo pode. Esclarece a autora que sua intenção, nessa reflexão sobre as pedagogias da sexualidade, foi questionar e problematizar as verdades construídas sobre o corpo e sobre a sexualidade. Acrescenta a afirmação de que ao "[...] fazer a história ou as histórias dessa pedagogia, talvez nos tornemos mais capazes de desarranjá-la, reinventá-la e torná-la plural." (LOURO, 2007, p.33).

Essa breve incursão a respeito da educação sexual com a qual nos comprometemos, convém para confirmarmos "à compreensão de que a sexualidade não é apenas uma questão pessoal, mas é social e política" e que a sexualidade "[...] é "apreendida", ou melhor, é construída, ao longo de toda a vida, de muitos modos, por todos os sujeitos." (LOURO, 2007, p.11). Para quem trabalha no âmbito das questóes sobre sexualidades e educação sexual, as compreensôes aqui apresentadas não são uma novidade. Porém, no Brasil, mais fortemente no ano de 2014, iniciou-se uma série de discussões em que, a nosso ver, houve uma equivocada preocupaçâo com as questóes que envolvem as temáticas de gênero e sexualidade nas escolas. Tratamos como equivocada, pois, a atenção se voltou não para a ampliação das discussões envolvendo estas realidades, ao contrário, a preocupação esteve em eliminar tal discussão do Plano Nacional de Educação (PNE).

4 Esta autora, professora na Universidade de São Paulo - USP, escreveu o livro "Educação Sexual: uma proposta, um desafio", publicado pela Editora Cortez no ano de 1985. 
O PNE 2014-2024 (BRASIL, 2014), sancionado em 15 de junho 2014 pela Lei $\mathrm{n}^{\circ} 13.005$, infelizmente, retirou do seu conteúdo o dispositivo que previa não só a promoção da igualdade de gênero e de orientaçáo sexual, como também a promoção da igualdade racial nos contextos escolares. Este cenário de retrocesso na linguagem jurídica presente na educação, evidenciou a força de um movimento fundamentalista no Brasil, representado na câmara federal por deputados da chamada "bancada evangélica" por deputados católicos conservadores. Preocupados em manter princípios que negam o gênero como uma construção histórica, social e cultural, bem como as múltiplas possibilidades de expressão das sexualidades e das formas contemporâneas de constituição familiar, estes setores conservadores tem negado a perspectiva de uma educação inclusiva pautada nos direitos humanos.

Elegemos a palavra retrocesso, pois, na década de 80 no Brasil, trabalhos voltados para uma política de emancipação da sexualidade já eram trazidos para o diálogo nas escolas. Antes mesmo disso, em 1970, Naumi de Vasconcelos apresentava sua Tese de Licenciatura em Sciense Sexologiques et Familiales, Essai d'une critique des dogmatismes sexuels, na Universidade Catholique de Louvain. Ou seja, desde então, muitas Instituiçóes de Ensino Superior no Brasil desenvolvem pesquisas voltadas a esta temática, representados em muitos grupos chancelados pelo $\mathrm{CNPQ}^{6}$. Isso sem mencionarmos todas as conquistas dos movimentos feministas, de enfretamento a homofobia, lesbofobia, transfobia e de direitos humanos ao longo do século XX e XXI. Todas essas conquistas de espaços e de visibilidades confirmam que não há mais como retroceder no campo das propostas educativas sua interface com as questóes relacionadas a gênero e sexualidade. Nesta direção, entendemos que "[...] o campo da sexualidade e da educação sexual, com ênfase nas relações de gênero, constitui espaço importante para a efetivação de propostas concretas de ação em que se combata a discriminação, o preconceito e a violência." (COSTA et al., 2009, p.5)

Diante das lutas históricas no que diz respeito à igualdade de gênero, ao casamento igualitário, ao uso do nome social pelos/as transexuais, entre outras conquistas, nos cabe questionar e reflexionar sobre: quais as implicações, em pleno século XXI, da existência de um movimento preocupado com a retirada das temáticas sobre a "promoção de igualdade de gênero e orientação sexual" dos planos que regem a educação brasileira? Quais linguagens sobre sexualidade, gênero, educação sexual foram sendo construídas ao longo do século XX e nesse início de século XIX? Como professores e professoras tem se posicionado? Que

5 Livro: "Os dogmatismos sexuais" publicado no Brasil, pela editora Paz e Terra, no ano de 1971.

6 Conselho Nacional de Desenvolvimento Científico e Tecnológico - CNPQ. 
significados estáo sendo produzidos nos espaços escolares? Quais palavras os/as docentes utilizam ou não em suas atuaçóes, explicaçóes e propostas com estas temáticas? Como a educação sexual, enquanto disciplina curricular em cursos de formação de docentes, tem sido ou não afetada?

Náo intencionamos aqui desenvolver respostas a todos esses questionamentos, embora saibamos que a construção de compreensóes precisa ser coletivamente pensada, pesquisada e problematizada, enfim, tensionada nos espaços de produçáo de saberes junto a docentes, educandos/as e demais profissionais presentes no espaço das escolas brasileiras. Nosso objetivo aqui é o de problematizar a educação sexual nos espaços de formação de professores/as e a sua relação com a produção de legislaçôes que intentam retirar do plano educativo as reflexôes sobre a "promoção da igualdade de gênero e orientação sexual". Para refletir sobre este cenário, nos ancoramos em algumas noções teóricas do filósofo contemporâneo Jacques Rancière. No diálogo com este autor e outros interlocutores, vislumbramos a possibilidade de uma reconfiguração da educação sexual na formação de professores/as e a construção, por parte dos docentes, de um posicionamento dissidente.

\section{A linguagem jurídica e as disputas no campo da educação}

Em 2011 iniciaram as discussóes das metas e estratégias para o ensino em todos os níveis - infantil, básico e superior - para os próximos dez anos. Tais discussóes foram sendo realizadas durante três anos até o momento da aprovação do atual PNE em 2014. O processo de construção coletiva de uma legislação nacional coaduna com os princípios democráticos que regem a Constituição Federal. É comum entendermos a democracia a partir de uma dimensão participativa em que sujeitos e coletivos, ao dialogarem sobre determinada questão, buscam concretizar uma decisão consensual entre as partes. Expressão desta perspectiva de democracia foi a elaboração do PNE.

Interessa-nos destacar aqui as polêmicas geradas em torno de umas das estratégias previstas no documento que foi elaborado em 2011. Naquele momento, a Meta 3 - que previa a universalização, até 2016, do atendimento escolar a todos com idade entre 15 a 17 anos e, até o final da vigência do PNE, a elevação da taxa de matrículas deste grupo no ensino médio para $85 \%$ demarcava, dentre suas estratégias, a necessidade de "[...] políticas de prevenção à evasão motivada por preconceito e discriminação à orientação sexual ou à identidade de gênero, criando rede de proteção contra formas associadas de exclusão." (BRASIL, 2011).

Como se pode observar, a primeira versão do PNE deixava clara a relação existente entre a evasão escolar e as diversas formas de preconceito e discriminação envolvendo as relaçóes de gênero e sexualidade. Sabe-se que "[...] 
as relaçóes sociais existentes na escola produzem representações de sexualidade e relaçôes de gênero que devem ser analisadas, pois em sua maior parte reproduzem preconceitos e estereótipos que geram situaçóes negativas entre meninos e meninas." (COSTA et al., 2009, p.4). Portanto, previa criar políticas de prevenção a estas violências. No entanto, durante os debates em torno do texto do PNE, a preocupação de setores fundamentalistas com estas questóes, como já salientado, forçou a retirada desta estratégia. O atual PNE 2014-2024, não menciona a palavra gênero nem orientação sexual e a estratégia descrita acima foi totalmente suprimida do texto.

No referido documento, encontramos no texto de abertura, intitulado " $\mathrm{A}$ história do PNE e os desafios da nova lei”, escrito por Paulo Sena - consultor legislativo da Câmara dos Deputados na Área de Educação, Cultura e Desporto as questóes polêmicas que envolveram o processo de construção do PNE. O autor demarca que:

A mais ruidosa polêmica diz respeito à alteração da diretriz que previa a superação das desigualdades educacionais (inciso III do art. $2^{\circ}$ do substitutivo da Câmara). O Senado alterou esse dispositivo, retirando a ênfase na promoção da "igualdade racial, regional, de gênero e de orientação sexual", expressão substituída por "cidadania e na erradicação de todas as formas de discriminação". A contenda terminou favorável ao Senado, com a aprovação do destaque para manter seu texto. (BRASIL, 2014, p.22).

A partir da aprovação do PNE, coube aos estados e municípios iniciarem a reformulação de seus planos de educação para alinharem-se com a proposta nacional. Sabe-se que, até o momento,

[...] deputados de ao menos oito Estados e vereadores de inúmeros municípios retiraram dos Planos Estaduais e Municipais de Educação metas e estratégias destinadas à superaçáo das desigualdades de gênero, de orientação sexual e de raça e ao combate às discriminaçôes no ambiente escolar que violam o direito humano à educaçáa 7 .

Diante deste cenário de retrocesso, pelo menos no que diz respeito a esta legislação educacional, vemos um recuo impresso na linguagem jurídica que

7 O Relatório do Governo brasileiro sobre a situação dos direitos das crianças e adolescentes do Brasil, apresentado dias 21 e 22 de setembro, durante a 70 Sessão do Comitê dos Direitos da Criança da ONU - Organização das Naçóes Unidas, em Genebra (Suíça), contém dentre os principais temas destacados no documento "os retrocessos na promoção da igualdade de gênero nos planos municipais de educaçáo“. Disponível em: <http://www.campanhaeducacao.org.br/?idn=1458>. Acesso em: 24 set. 2015. 
versa sobre as relaçóes de gênero e sexualidade nas escolas, o que nos provoca a pensar sobre os seus efeitos na formação de professores e professoras. Faz-nos refletir sobre os agenciamentos que este discurso conservador, sexista, a-histórico e opressor pode vir a efetuar no campo das práticas pedagógicas cotidianas, na formação de docentes, nas escolas públicas e privadas brasileiras, dando especial atenção "a legalidade que oferecem para que tais discussôes ocorram neste cenário” (LEÃO; RIBEIRO, 2012, p.29).

Neste contexto, observamos que há outros documentos educacionais em vigor, como é o caso do Plano Nacional de Educação em Direitos Humanos (PNEDH), onde, em consonância com o Programa Mundial de Educação em Direitos Humanos, prevê que a educação, em todos os seus níveis, deve contribuir para "[...] a promoção e a valorização das diversidades (étnico-racial, religiosa, cultural, geracional, territorial, físico-individual, de gênero, de orientação sexual, de nacionalidade, de opçấo política, dentre outras)." (BRASIL, 2007, p.18). Explicitamos que há um movimento que considera a pluralidade de modos de vida e a importância de um trabalho crítico nos espaços escolares que dialogue, problematize e considere as dimensóes de gênero e sexualidade em toda a sua historicidade, porém, ao mesmo tempo, vemos a presença de um movimento que intenciona silenciar essa perspectiva.

Para sintetizarmos esse cenário, sob o qual convidamos os/as docentes a refletirem, não podemos deixar de mencionar a conquista que foi a elaboração dos Parâmetros Curriculares Nacionais (PCNs), em que consta uma proposta de "orientação sexual" prevendo os seguintes temas transversais para a educação básica: ética, saúde, meio ambiente, orientação sexual, pluralidade cultural, trabalho e consumo (BRASIL, 1998), sendo que estes deveriam ser incorporados às disciplinas curriculares e trabalhos educativos já existentes nas escolas. Os PCNs foram elaborados pelo Ministério da Educação (MEC) em parceria com Secretaria de Educação Fundamental (SEF) e a Secretaria de Educação Média e Tecnológica, no período de 1995 a 1998. Os PCNs objetivaram apontar para a comunidade educacional a política de formação governamental. No entanto, a Câmara de Educação Básica do Conselho Nacional de Educação (CNE) considerou que a forma como os PCNs foram elaborados aconteceu de forma inversa. Chegaram à conclusão de que um documento mais restrito estava definindo orientaçôes para um documento de maior importância como é o caso das Diretrizes Curriculares Nacionais, o que fez com que o CNE instituísse um caráter não obrigatório aos PCNs.

Deste modo, entendemos que este é um campo em disputa. Um campo que, por meio da linguagem jurídica, intenta pleitear os espaços políticos e sociais educativos. Ao retirar determinadas palavras e expressóes das legislaçóes, se imprime o que se deve ou não falar, o que é ou não preciso dizer sobre 
determinados assuntos na escola e, consequentemente, na formação de docentes. Além disso, se constrói uma ideia de consenso sobre determinada questão, a partir do momento em que esta passa por um longo período de discussão coletiva nas esferas democráticas do país. Um processo que, neste caso, tencionou um vácuo na possibilidade de conversação nas escolas. Mas, por outro lado, por conta da própria linguagem jurídica na educação não se apresentar de modo consensual, como vimos acima, ela revela a existência de "um conflito sobre a configuração do mundo sensível” (RANCIÈRE, 2006, p.373) que precisa ser olhado por nós.

Assim, é urgente "[...] a necessidade de dialogarmos com enunciados que coincidem com uma racionalidade jurídica, para polemizar e olhar para o que ela produz nos contextos escolares." (GROFF, 2015, p.134). Faz-se necessário problematizar a força destas legislaçóes na configuração e reconfiguração das escolas. Como a lei se expressa na linguagem da convivência educativa cotidiana? Quais os seus efeitos no estudo das disciplinas que abordam a educação sexual na formação de docentes? E ainda: o predomínio da linguagem jurídica na educação condiciona a perda da responsabilidade ética com o outro? ${ }^{8}$ Há a produção de um dissenso capaz de invisibilizar e amordaçar as diferenças de gêneros e sexualidades?

\section{Entre legislações e práticas educativas: diálogos teóricos}

Diante do cenário aqui apresentado, desse breve olhar sobre o campo de disputa nos conteúdos das legislaçóes e que certamente afetam os/as docentes em seus espaços educativos, nos colocamos a pensar sobre a formação docente. Este contexto nos provoca a reavaliar também a importância de uma formação crítica e questionadora voltada para o processo de elaboração destes documentos. Uma formação que viabilize reflexóes sobre os efeitos das legislaçóes nas relaçóes educativas, bem como sobre a própria ideia de democracia participativa. Alertamos que não somos contrárias à participação, entretanto, vislumbramos a importância de uma concepção outra de democracia. Uma democracia radical e plural que transfigure a própria noção habitual de política e/ou participação política.

A ideia de uma democracia radical e plural expressa nas teorizaçóes de autores contemporâneos como Chantal Mouffe, Ernesto Laclau e Jacques Rancière, vem ratificar que a única forma de salvaguardar a democracia

8 Esta questão emerge das reflexóes realizadas por Skliar (2014), quando este problematiza o predomínio da razão e da linguagem jurídica na educaçáo ao se sobrepor à linguagem da convivência, condicionando a perda da responsabilidade ética com o outro. 
seria instalar um descontentamento, um dissenso. Esses autores caminham contrários à ideia de consenso presente nos posicionamentos de uma democracia participativa. Para eles, todo consenso expressa uma forma de exclusão. Como explicita Mouffe (2003, p.11) “[...] o tipo de teoria política democrática dominante atualmente não pode nos ajudar a entender a importância do dissenso numa sociedade democrática.”, até mesmo porque, o dissenso, o conflito e a tensão, para racionalidade moderna, são sinônimos de desordem, caos e incivilidade. Ou seja, o conflito se apresenta como um perigo para lógica de uma gestão democrática que se pauta na busca pelos acordos consensuais.

Prado (2013) $)^{9}$ nos explica que a consequência de uma visão de democracia radical e plural, a que estamos convidando os/as docentes a pensarem, é a de assumir que o dissenso e o conflito fazem parte da vida social de uma maneira inerradicável. Não há como não existirem conflitos na ordem social e, deste modo, o dissenso é entendido como constituinte da vida e o cerne do que Rancière (1996, 2006, 2010, 2014) entende por sendo a política. A política para Rancière (2006, p.368) náo é a forma como "[...] indivíduos e grupos em geral combinam seus interesses e sentimentos. É antes um modo de ser da comunidade que se opóe a outro modo de ser, um recorte do mundo sensível que se opóe a outro recorte do mundo sensível."

A política acontece, então, quando um conflito coloca em evidência a existência de outros mundos. Ou seja, evidencia que náo há apenas um modo de funcionamento das coisas, que não há apenas um modo de ser homem e de ser mulher, que não há uma verdade sobre a sexualidade, enfim, que não há apenas um mundo possível. Assim, política aparece quando o argumento consensual é questionado, e o que era considerado como inquestionável "[...] irrompe diante de olhos acostumados à normalidade (e à normalização) e promove rupturas." (MARQUES; SENA, 2013, p.7). Com isso, a política dá visibilidade a outros modos de ser e viver, mostrando que há uma partilha do mundo sensível, isto é, "[...] partilha de espaços, tempos e tipos de atividades que determina propriamente a maneira como um comum se presta à participação e como uns e outros tomam parte nessa partilha.” (RANCIÈRE, 2014, p.15).

As colocaçóes de Rancière sobre a partilha do sensível, na ideia de que há um comum que é partilhado e que existem lugares e partes determinadas, e, no entanto, há aqueles que tomam ou não tomam parte nessa partilha, posicionam o autor a diferenciar aquilo que ele entende como política em relação ao que ele

9 Apontamentos registrados no Curso Por que estudar política? Ministrado pelo Programa de Pós-Graduação em Psicologia, na Universidade Federal de Santa Catarina, pelo professor Dr. Marco Aurélio Máximo Prado da Universidade Federal de Minas Gerais. 
chama de gestão ou de polícia. Costuma-se designar com "a palavra politica o conjunto dos processos pelos quais se operam a agregação e o consentimento das coletividades, a organização dos poderes e a gestão das populações", inclusos aí "a distribuição dos lugares e das funções e os sistemas de legitimação dessa distribuição" (RANCIĖRE, 2006, p.372, grifo do autor). Contudo, o autor propóe para esse conjunto de processos comumente chamado de política, a denominação de polícia ou gestão.

Proponho chamá-lo de polícia, ampliando portanto o sentido habitual dessa noção, dando-lhe também um sentido neutro, não pejorativo, ao considerar as funçóes de vigilância, de repressáo habitualmente associados a essa palavra como formas particulares de uma ordem muito mais geral que é a da distribuição sensível dos corpos em comunidade. (RANCIÈRE, 2006, p.372).

Acrescentamos que é "a ordem do visível e do dizível que determina a distribuição das partes e dos papéis ao determinar primeiramente a visibilidade mesma das "capacidades" e das "incapacidades" associadas a tal lugar ou a tal função" (RANCIĖRE, 2006, p.372). Em outras palavras, a polícia diz respeito a um determinado ordenamento que é vivido como natural, em que há uma clara hierarquização social constituída a partir da definição das funçóes de cada um e de cada uma na comunidade. Este ordenamento, intenta, a todo o momento, nos dizer que nele todos fazem parte, de que todos são contados. Não obstante, ao ampliar o conceito de polícia, Rancière $(2006,2010)$ restringe então o seu entendimento do que é a política:

Proponho reservar a palavra politica ao conjunto das atividades que vêm perturbar a ordem da polícia pela inscriçâo da pressuposição que lhe é inteiramente heterogênea. Essa pressuposição é a igualdade de qualquer ser falante com qualquer outro ser falante. Essa igualdade não se inscreve diretamente na ordem social. Manifesta-se apenas pelo dissenso, no sentido mais originário do termo: uma perturbação no sensível, uma modificação singular do que é visível, dizível, contável. (RANCIÈRE, 2006, p.372, grifo do autor).

Como é possível identificar nas explicações do autor, o dissenso é de suma importância e deve ser observado não como "oposição entre um governo e pessoas que o contestam” (RANCIÈRE, 2006, p.373), mas como um conflito na configuração do sensível, isto é, a perturbação de espaços destinados a um determinado fim, a reconfiguração de determinadas normas e lugares sociais. Dessa forma, a política não é uma luta de classes ou de partidos, "[...] a política é um conflito sobre a configuraçâo do mundo sensível na qual podem aparecer atores e objetos desses conflitos." (RANCIÈRE, 2006, p.373) como, por 
exemplo, a luta dos coletivos para a reconfiguração de normativas que colocam a "igualdade de gênero e orientação sexual" nas políticas educacionais.

Como elucida Prado (2013) é exatamente na compreensão desse conflito que reside a raiz de uma democracia radical e plural, pois não há como excluir o conflito da vida social. Assim, quando olhamos para os documentos que legislam sobre a educação brasileira, observamos nestes a coexistência de perspectivas divergentes que, no entanto, podem vir a se tornar discursos monológicos nas práticas pedagógicas, a partir da eleição de apenas uma única perspectiva. É preciso que esta divergência, ou seja, que estes discursos possam ganhar relevo nos espaços educativos com o intuito de instaurar dissensos. É o dissenso que dá visibilidade e lugar de discurso para as múltiplas possibilidades de vivência dos gêneros e das sexualidades. É preciso, nesse sentido, possibilitar a emergência de sujeitos políticos capazes de polemizar a especificidade da gestão/polícia e, deste modo, concretizar a democracia, como pensada pelos nossos interlocutores neste texto.

\section{Um convite ao dissenso}

Sabemos da complexidade das reflexóes postas aqui a respeito da democracia e do dissenso. No entanto, antes de desenvolver com densidade as noçóes filosóficas que envolvem estes conceitos, nos preocupamos em utilizá-los como dispositivos articuladores de nossa reflexão sobre a relação entre a educação sexual na formação de professores e as legislaçóes educativas. A linha de nossas argumentaçóes encontraram os limites de uma escrita breve, como também os limites de um ensaio teórico em construção. Contudo, reconhecemos nos escritos do filósofo francês, um diálogo potente e em aberto com o campo da educação e, mais especificamente, com os aspectos polêmicos que envolvem a educação sexual e as questóes relacionadas a gêneros e sexualidades. Rancière é um autor que não deseja seguidores, muito menos prescreve caminhos. $\mathrm{O}$ que concretizamos neste momento, a partir da leitura de alguns de seus escritos, foi o início de um diálogo e um convite ao dissenso.

Entendemos que é de primordial importância que os educadores e educadoras não condicionem suas ações, na intenção de um diálogo ou da problematização sobre gêneros e sexualidades, por exemplo, às decisóes do campo consensual ou às legislaçóes que intencionam silenciar as diferenças e a pluralidade dos modos de vida presentes no universo escolar. Sabe-se que "[...] a escola se tornou palco onde a sexualidade se manifesta com todo o seu vigor, mas encontra a indiferença, a negação e o preconceito quando foge da norma culturalmente estabelecida." (COSTA et al., 2009, p.4). Portanto, é preciso que a formação de docentes abarque esse diálogo a respeito do que o consenso produz e, sobretudo, contemple a importância do dissenso para que a tarefa da democracia se concretize. 
Tal tarefa é a de criar um campo de litígio capaz de dar visibilidade e discursividade ao que até então se apresentava como um consenso natural. Provocar o dissenso no âmbito da educação e, mais especificamente, no campo de estudos da educação sexual na formaçáo de professores/as, implica a "[...] construção de formas potencializadoras de pensar, sentir e agir em relação à sexualidade, sendo essas subversivas às normas e aos preceitos jurídicos, religiosos, morais ou educacionais que discriminam sujeitos." (GESSER et al., 2012, p.233). Envolve também uma educação sexual que diverge de tudo aquilo que é dado como normal; que contesta a unicidade do mundo; que se responsabiliza eticamente com o outro; que entende que a democracia só se realiza, no seu aspecto mais profundo, quando há uma reconfiguração do mundo sensível na qual a parte dos sem-parte toma o lugar da configuração.

Por fim, registramos nosso convite para que professores e professoras produzam dissensos em suas práticas, por meio do seu comprometimento com os direitos humanos, com as lutas históricas dos movimentos feministas e de gays, lésbicas, bissexuais, transexuais, travestis e transgêneros. O convite é para que exerçam uma relação educativa na escola sem se eximir das interferências necessárias diante das discriminaçóes e opressóes de gênero, diante da homofobia, lesbofobia e transfobia. E ainda, uma atuação que potencialize as diferenças como realidade relacional e afirmadora da dialogia da vida, em detrimento de discursos monológicos, fundamentalistas e sexistas que intentam estratificar e embrutecer ${ }^{10}$ os corpos e a vitalidade do mundo.

10 Para Rancière há um método embrutecedor "que provoca no pensamento daquele que fala o sentimento de sua própria incapacidade" (VERMEREN; CORNU; BENVENUTO, 2003, p.188). 


\section{REFERÊNCIAS}

BRASIL. Plano Nacional de Educaçáo 2014-2024: Lei no 13.005, de 25 de junho de 2014, que aprova o Plano Nacional de Educação (PNE) e dá outras providências. Brasília: Câmara dos Deputados, Ediçóes Câmara, 2014. Disponível em: <http://www.observatoriodopne.org. br/uploads/reference/file/439/documento-referencia.pdf>. Acesso em: 26 set. 2015.

$\begin{array}{cccc}\text { - Plano Nacional de Educação 2011-2020: Projeto de Lei. Brasília, } \\ \text { 2011. } & \begin{array}{c}\text { Disponível } \\ \text { em: }\end{array} & <\text { http://portal.mec.gov.br/index.php?option=com }\end{array}$ docman\&view=download\&alias=7116-pl-pne-2011-2020\&Itemid=30192>. Acesso em: 20 maio 2014.

Plano Nacional de Educaçáo em Direitos Humanos. Brasília: Ministério da Educação, Minstério da Justiça, Secretaria Especial dos Direitos Humanos, UNESCO, 2007.

Parâmetros Curriculares Nacionais: apresentação dos temas transversais. Brasília: Ministério da Educação, Secretaria de Educação Fundamental, 1998. Disponível em: <http://portal.mec.gov.br/seb/arquivos/pdf/ttransversais.pdf>. Acesso em: 20 dez. 2014.

COSTA, A. P. et al. Sexualidade, gênero e educação: novos olhares. Revista IberoAmericana de Estudos em Educaçáo, Araraquara, v.4, n.1, 2009. Disponível em: <http:// seer.fclar.unesp.br/iberoamericana/article/view/2691/2401>. Acesso em: 20 dez. 2014.

FIGUEIRÓ, M. N. D. Formaçáo de educadores sexuais: adiar não é mais possível. Campinas: Mercado de Letras; Londrina: EDUEL, 2006.

GESSER, M. et al. Psicologia escolar e formação continuada de professores em gênero e sexualidade. Psicologia escolar e educacional, Campinas, v.16, n.2, p.229-236, 2012.

GROFF, A. R. Entre vozes e linguagens para enunciar a violência: análise dialógica de uma experiência de formação continuada para professores/as. 2015. 270f. Tese (Doutorado em Psicologia) - Universidade Federal de Santa Catarina, Florianópolis, 2015.

LEÃO, A. M. de C.; RIBEIRO, P. R. M. As políticas educacionais do Brasil: a (in) visibilidade da sexualidade e das relaçóes de gênero. Revista Ibero-Americana de Estudos em Educaçáo, Araraquara, v.7, n.1, p.28-37, 2012.

LOURO, G. L. O corpo educado: pedagogias da sexualidade. 2.ed. Belo Horizonte: Autêntica, 2007.

MARQUES, A. C. S.; SENNA, G. A política e a estética em lixo extraordinário: dano, dissenso e desidentificação. Novos Olhares: Revista de Estudos sobre Práticas de Recepçáo a Produtos Midiáticos, Sáo Paulo, v.2, n.2, p.6-17, 2013.

MOUfFE, C. Democracia, cidadania e a questão do pluralismo. Política \& Sociedade: Revista de Sociologia Política, Florianópolis, n.3, p.11-26, out. 2003.

RANCIÈRE, J. A partilha do sensível: estética e política. 2.ed. São Paulo: EXO experimental: 34, 2014. 
- Nossa ordem policial: o que pode ser dito, visto e feito. Urdimento: Revista de Estudos em Artes Cênicas, Florianópolis, v.1, n.15, p.81-90, out. 2010.

. O dissenso. In: NOVAES, A. A crise da razão. São Paulo: Companhia das Letras: Ministério da Cultura: Fundação Nacional de Arte, 2006. p.367 - 382.

O desentendimento: política e filosofia. São Paulo: 34, 1996.

SKLIAR, C. Desobedecer a linguagem: educar. Belo Horizonte: Autêntica, 2014.

VERMEREN, P.; CORNU, L.; BENVENUTO, A. Atualidade de o mestre ignorante. Educaçáo \& Sociedade, Campinas, v.24, n.82, p.185-202, abr. 2003. 


\section{Resumo}

\section{A educação sexual e a formação de professoreslas um convite ao dissenso}

Este artigo apresenta um olhar acerca da educação sexual, como ela vem sendo compreendida historicamente no cenário educativo brasileiro, bem como os avanços, retrocessos e desafios que ela tem enfrentado no âmbito das politicas educacionais atuais. Nosso objetivo é problematizar a educação sexual nos espaços de formação de professores/as e a sua relaçáo com a produção de legislaçóes que intentam retirar do plano educativo as reflexóes sobre a "promoção da igualdade de gênero e orientação sexual". Para refletir sobre este cenário, nos ancoramos nas noçóes de dissenso, gestão e democracia, do filósofo francês Jacques Rancière. No diálogo com este autor, abrimos a possibilidade para que professores e professoras adentrem este campo de sensibilidade desde uma posição dissidente, no sentido de produzir outras reconfiguraçóes em torno da educação sexual nas escolas.

Palavras-chave: Educação sexual. Formação de professores/as. Legislações. Dissenso. Jacques Rancière.

\section{Abstract}

Sex education and the training of teachers an invitation to dissent

In this work, we present a look about sexual education, as it has been historically understood in the Brazilian educational setting, as well as advances, setbacks and challenges it has faced in the context of current educational policies. Our intention is to discuss sex education in teacher training spaces and their relationship with the production of laws that aim to remove reflections on the "promotion of gender equality and sexual orientation" from the educational plan. To reflect on this scenario we anchored in notions of dissensus, management and democracy, by the French philosopher Jacques Rancière. In dialogue with the author, we opened the possibility for teachers access this field of sensibility from a dissident position, to produce other reconfigurations around sexual education in schools.

Keywords: Sex education. Teacher training. Laws. Dissensus. Jacques Rancière. 